\title{
Is a diet low in greenhouse gas emissions a nutritious diet? - Analyses of self-selected diets in the LifeGene study
}

\author{
Katarina Bälter ${ }^{1,2,3^{*}}$, Camilla Sjörs ${ }^{1}$, Arvid Sjölander ${ }^{1}$, Christopher Gardner ${ }^{2}$, Fredrik Hedenus ${ }^{4}$ and Annika Tillander ${ }^{1}$
}

\begin{abstract}
Background: Climate change is an urgent global issue and the food sector is a major contributor to greenhouse gas emissions (GHGE). Here we study if a diet low in GHGE could be a nutritious diet compared to the Nordic Nutrition Recommendations (NNR).

Methods: The environmental impact of foods from Life Cycle Assessment (LCA) data was linked to a food frequency questionnaire (FFQ) filled out by 5,364 participants in the Swedish LifeGene study. Thereafter, we calculated the daily emission of $\mathrm{CO}_{2}$ equivalents $\left(\mathrm{CO}_{2} \mathrm{e}\right)$ as well as the intake of selected nutrients associated with vegetables, fruits, meat and dairy products. The $\mathrm{CO}_{2} \mathrm{e}$ was divided into quartiles were quartile 1 corresponds to a diet generating the lowest $\mathrm{CO}_{2} \mathrm{e}$, and quartile 4 corresponds to a diet with the highest $\mathrm{CO}_{2} \mathrm{e}$.
\end{abstract}

Results: The overall diet-related emission was $4.7 \mathrm{~kg} \mathrm{CO} 2 \mathrm{e} /$ day and person, corresponding to 1.7 ton $\mathrm{CO}_{2} \mathrm{e} /$ year. In general, there were only small differences in nutrient intake between groups of varying levels of $\mathrm{CO}_{2} \mathrm{e}$, regardless if the intake was analyzed as absolute intake, energy percent or as nutrient density. Moreover, adherence to NNR was high for the group with the lowest $\mathrm{CO}_{2} \mathrm{e}$, except for saturated fat where the intake was higher than recommended for all $\mathrm{CO}_{2} \mathrm{e}$ groups. On the other hand, only the group with the lowest $\mathrm{CO}_{2} \mathrm{e}$ fulfilled recommended intake of fiber. However, none of the $\mathrm{CO}_{2} \mathrm{e}$ groups reached the recommended intake of folate and vitamin $\mathrm{D}$.

Conclusions: Here we show that a self-selected diet low in $\mathrm{CO}_{2}$ e provides comparable intake of nutrients as a diet high in in $\mathrm{CO}_{2} \mathrm{e}$.

Keywords: Diet, Nutrients, Carbon dioxide equivalents, Greenhouse gas emission, Life cycle assessment, Nordic Nutrition Recommendations, LifeGene study

\section{Background}

Substantial reductions of greenhouse gas emissions (GHGE) are needed if the global warming should be limited to the UN target of a maximum of $2{ }^{\circ} \mathrm{C}$, compared to pre-industrial times, and dietary shifts towards a more climate friendly diet are one of several strategies to reduce emissions from the food sector [1-3]. However, when promoting a diet low in GHGE, it is important to consider health aspects of the diet and adherence to dietary recommendations. Previous studies based on

\footnotetext{
* Correspondence: Katarina.Balter@ki.se

'Department of Medical Epidemiology and Biostatistics, Karolinska Institutet, Nobels väg 12a, 17177 Stockholm, Sweden

${ }^{2}$ Stanford Prevention Research Center, Stanford School of Medicine, Stanford, USA

Full list of author information is available at the end of the article
}

simulated dietary scenarios have reported that a diet low in GHGE can be nutritious at the same time $[2,4,5]$, but among studies based on self-selected diets [6-9], only one reported GHGE in relation to the intake of macronutrients and fiber [10]. Therefore, more research is needed to study intake of vitamins, minerals, macronutrients and fiber among individuals with a diet low in GHGE [11].

The production of food is estimated to contribute to $25 \%$ of the total GHGE in the world, more than the total emissions from the transport sector [12]. However, there is a substantial variation in GHGE for different food products and the production of food items from animal origin is generally associated with higher GHGE than plant-based food items, such as vegetables, whole grains 
and legumes. Particularly, meat from ruminants, such as cattle and sheep, are associated with high emissions due to their less efficient feed-conversion rate and to the methane produced during digestion [13, 14]. Our collective food choices have significant impact on global GHGE and a dietary shift may significantly impact public health.

Here we estimate diet-related GHGE in the Swedish LifeGene study using a Food Frequency Questionnaire (FFQ) linked to Life Cycle Assessment (LCA) data of carbon footprint for food products representative for Swedish food habits. The overall aim is to investigate if a diet low in GHGE can be a nutritious diet. To the best of our knowledge this is the first Swedish study reporting the intake of several nutrients from a self-selected diet low vs. high in GHGE. Second, it is the first study relating GHGE to the Nordic Nutritional Recommendations (NNR) [15] on an individual level for nutrients associated with meat, dairy, fruits and vegetables.

\section{Methods}

The LifeGene study is a prospective Swedish cohort study aiming at combining advances in modern biotechnology with information on individual's health and lifestyle [16]. The target enrollment in LifeGene is 300,000 Swedes, with the projected follow up of 20 years [17]. The present study is based on the pilot phase of the LifeGene study, which was launched in Stockholm in October 2009, followed by Umeå in November and Alingsås in January 2010, and invitations were sent out until March 31, 2010. In total, 42,700 women and men age 18-45 years old were randomly selected through the national population registry and invited to the study. An invitation letter with personal login information was sent out, including up to three reminders. After the study participants agreed to participate and left consent on the LifeGene web page, they were asked to respond to a comprehensive interactive web questionnaire at home, including questions on lifestyle factors, self-care, women's/men's health, living habits, health history, injuries, asthma and allergy, mental health, home and work. Thereafter, an appointment at one of the test centers was made for in-person testing. 7,818 filled out part of, or the whole questionnaire, and 6,633 visited the test center. The Research Ethics Review Board at Karolinska Institutet approved the present study.

\section{Dietary assessment method}

Diet was assessed using the interactive web-and meal based FFQ called Meal-Q, described in detail elsewhere $[18,19]$. Meal-Q assesses habitual dietary intake during the previous months and includes 102-174 food items, dishes, and beverages, depending on the number of follow-up questions, as well as questions about supplement use, meal patterns, and eating behavior. Participants were instructed to choose among predefined food items and intake frequencies and report on all items that were consumed at least once a month. Five photos of different portion sizes were included for 1) rice, potatoes and pasta, 2) meat, chicken, fish and vegetarian substitutes and 3) vegetables (raw or cooked) and used to calculate portion sizes for cooked dishes and vegetables whereas a standard portion sizes were used for all other food items. A program tailored for Meal-Q called NutriCalc was used to link dietary data to the national food composition table from the Swedish National Food Agency [20] to generate the daily intake of energy and nutrient per person. MealQ has been validated using 7-day weighed food records with regards to nutrients and energy as well as doubly labeled water with regards to energy, demonstrating good validity and reproducibility $[18,19]$.

\section{Diet-related GHGE}

We identified published LCA data for 65 food items and food groups representative of typical food consumption in Sweden described in detailed elsewhere and about half of the LCA data came from the same source [21]. These 65 food items and groups matched the food items/questions in Meal-Q, for example, we asked for 3 kinds of bread in Meal-Q (white, whole grain and crisp, respectively), but applied the same LCA data for all 3 kinds of bread. Assessment of the combined impact of different greenhouse gases was achieved using Global Warming Potential (GWP) with a 100 years perspective expressed as $\mathrm{kg}$ carbon dioxide equivalents $\left(\mathrm{CO}_{2} \mathrm{e}\right)$ per $\mathrm{kg}$ of food product. The GWP used to calculate the $\mathrm{CO}_{2} \mathrm{e}$ was 1 for carbon dioxide, 34 for methane and 296 for nitrous oxide [22].

The GHGE include emissions from agriculture and its inputs, food processing, distribution and retailing [21]. If LCA studies did not include emissions from distribution and retailing, emission were imputed by adding emissions linked to retail, transportation and packaging using Swedish data [21]. Emissions after the retail phase were not included, such as transports to the household, storing and cooking, as well as from waste management.

Portion sizes in Meal-Q were based on food ready to be eaten and therefore we recalculated LCA data for uncooked food to $\mathrm{CO}_{2} \mathrm{e}$ per $\mathrm{kg}$ cooked food when needed, considering both hydration, i.e. cooking of rice, and dehydration, i.e. cooking of meat [21]. In addition, we adjusted for unavoidable food losses (i.e. shell and bone) using data from the Swedish food composition database [20] and avoidable food waste both before and after food preparation using data from the British Waste and Resources Action Programme [23] and a FAO report [24].

$\mathrm{CO}_{2} \mathrm{e}$ for mixed dishes was based on up to three main food products or groups and weighed using standard recipes from the Swedish food composition database [20], for example, lasagna was based on weighted LCA 
data from ground meat, milk and tomato, respectively. Thereafter, data on $\mathrm{CO}_{2} \mathrm{e}$ per $\mathrm{kg}$ food item were linked to all food items in Meal-Q by the NutriCalc program to calculate daily $\mathrm{CO}_{2} \mathrm{e}$ per person. The assessment of $\mathrm{CO}_{2} \mathrm{e}$ by Meal-Q was validated using 7-day weighed food records and the Spearman correlation coefficient between $\mathrm{CO}_{2} \mathrm{e}$ from Meal-Q and the 7-day weighed food records were $r=0.70$ (95\% CI 0.61-0.77), whereas 90\% were categorized into the same/adjacent quartile in crossclassification analyses [21]. The intraclass correlation coefficient for the reproducibility of Meal-Q was $0.81(95 \% \mathrm{CI}$ $0.73-0.87$ ), and $94 \%$ were categorized into the same/adjacent quartile in cross-classification analyses [21].

\section{Nordic nutritional recommendations (NNR)}

The main goal for the NNR is to set guidelines to promote good health and to prevent major chronic diseases in the population in the Nordic countries [15]. The NNR includes recommendations regarding intake of nutrients; total energy intake, intake of macronutrients as a percentage of total energy intake, intake of fiber and salt, as well as recommended daily intake of vitamins and minerals. Selected recommendations of relevance for the present study are described in Table 1.

\section{Test centers}

The in-person clinical testing included measurements of weight, height, waist, hip and chest circumference, bioimpedance, heart rate and blood pressure along with audiometry and spirometer. Blood and urine samples were taken for analyses and biobanking.

\section{Statistical analysis}

Participants with energy intake less than 3,300 or more than $21,000 \mathrm{~kJ}$ were excluded $(n=212)$. The purpose of the cut-off is to exclude participants with implausibly high or low total calorie intake, thus, improving the quality of the data that is being analyzed. Quartiles were used to split $\mathrm{CO}_{2} \mathrm{e}$ into four groups, both for crude values and energy adjusted values using the residual method [25] and quartile 1 corresponds to the group with the lowest $\mathrm{CO}_{2} \mathrm{e}$, and quartile 4 to the group with the highest $\mathrm{CO}_{2} \mathrm{e}$. Median and interquartile range $\left(25^{\text {th }}-75^{\text {th }}\right.$ percentile) of the nutrient intake divided by $\mathrm{CO}_{2} \mathrm{e}$ groups was calculated and the difference tested with Kruskal-Wallis test. To show the distribution within the energy adjusted $\mathrm{CO}_{2} \mathrm{e}$ groups, the nutrients are presented as boxplots in Figs. 2 and 3. The notch corresponds to the median, the edges of the box correspond to the first quartile $\left(q_{1}\right)$ and third quartile $\left(q_{3}\right)$. The vertical lines at the end of the dotted line are the lower and upper adjacent value (LAV and UAV) here calculated as follows: $\mathrm{LAV}=$ smallest value which is $\geq q_{1}-4$ $I O R$; UAV = largest value which is $\leq q_{3}+4 I O R$, where IQR is the interquartile range $\left(I O R=q_{3}-q_{1}\right)$. Due to large
Table 1 Description of the recommendations in the Nordic Nutrition Recommendations (NNR) from 2012

\begin{tabular}{|c|c|c|c|}
\hline & \multicolumn{2}{|c|}{$\begin{array}{l}\text { Recommended } \\
\text { intake }^{a}\end{array}$} & \multirow{2}{*}{$\begin{array}{l}\text { Goal for menu } \\
\text { planning } \\
\text { Nutrient/MJ }\end{array}$} \\
\hline & Women & Men & \\
\hline$\overline{\text { Energy }(\mathrm{kJ})^{\mathrm{C}}}$ & 8,500 & 11,000 & \\
\hline Protein $(E \%)^{d}$ & $10-20$ & $10-20$ & \\
\hline Carbohydrates (E\%) & $45-60$ & $45-60$ & \\
\hline Fat $(E \%)^{d}$ & $25-40$ & $25-40$ & \\
\hline Saturated fat $(E \%)^{d}$ & $<10$ & $<10$ & \\
\hline Monounsaturated fat $(E \%)^{d}$ & $10-20$ & $10-20$ & \\
\hline Polyunsaturated fat (E\%) ${ }^{d}$ & $5-10$ & $5-10$ & \\
\hline$\beta$-carotene $(\mu \mathrm{g})^{\mathrm{e}}$ & - & - & - \\
\hline Vitamin C (mg) & 75 & 75 & 8 \\
\hline Folate $(\mu \mathrm{g})$ & $300 / 400^{f}$ & 300 & 45 \\
\hline Fiber (g) & $25-35$ & $25-35$ & 3 \\
\hline Vitamin B12 $(\mu \mathrm{g})$ & 2.0 & 2.0 & 0.2 \\
\hline Iron (mg) & $9 / 15^{9}$ & 9 & 1.6 \\
\hline Zinc (mg) & 7 & 9 & 1.1 \\
\hline Vitamin D $(\mu \mathrm{g})$ & 10 & 10 & 1.3 \\
\hline Retinol $(\mu \mathrm{g})^{\mathrm{e}}$ & - & . & . \\
\hline Retinol equivalents (RE) ${ }^{h}$ & 700 & 900 & 80 \\
\hline Calcium (mg) & 800 & 800 & 100 \\
\hline
\end{tabular}

${ }^{\mathrm{a}}$ Recommended intake for women and men age 18-60 years

${ }^{b}$ Goals for menu planning expressed as nutrients/MJ for age 6-65 taking into account sub-groups with the highest nutrient requirements in the population ${ }^{c}$ Reference values for a person age 31-60 with a BMI of 23 with sedentary work

${ }^{d}$ Not including energy from alcohol. 1 gram of fat $=37 \mathrm{~kJ}, 1$ gram of protein $=$ $17 \mathrm{~kJ}, 1 \mathrm{gram}$ of carbohydrate $=17 \mathrm{~kJ}$

${ }^{\mathrm{e}} \mathrm{No}$ value determined

${ }^{f}$ Women in child-bearing age

${ }^{9}$ Menstruating women

${ }^{h} 1$ Retinol equivalents $(\mathrm{RE})=1 \mu \mathrm{g}$ retinol $=12 \mu \mathrm{g} \beta$-carotene

sample size we chosen 4 instead of commonly used 1.5 to highlight extreme observations to make more distinguishable graphs. The extreme observations, values below the LAV or above UAV, are marked as circles. All analyses were performed in the statistical software STATA version 13.1. Significance level was set to $\alpha=0.05$.

\section{Results}

In total, 5,576 participants filled out the section about diet in the questionnaire, of which 5,364 also visited the test center. Table 2 shows the characteristics of the study participants. The majority of participants had a normal BMI of $<25 \mathrm{~kg} / \mathrm{m}^{2}$, had more than a high school education and the overall median age was 32 years. The crude median diet-related emission was $4.7 \mathrm{~kg} \mathrm{CO}_{2} \mathrm{e} /$ day and person, corresponding to 1.7 ton $\mathrm{CO}_{2} \mathrm{e} /$ year, and the median emissions were lower for women, $4.4 \mathrm{~kg} \mathrm{CO}_{2} \mathrm{e} /$ day and person, than for men, $5.3 \mathrm{~kg} \mathrm{CO} \mathrm{CO}_{2} \mathrm{e} /$ day. $23 \%$ and $22 \%$ of the women and men, respectably, reported using 
Table 2 Characteristics of the participants in the Swedish LifeGene study in 2009-10

\begin{tabular}{|c|c|c|c|c|c|c|}
\hline \multirow[t]{3}{*}{ Characteristics } & \multicolumn{2}{|l|}{ Women } & \multicolumn{2}{|l|}{ Men } & \multicolumn{2}{|l|}{ All } \\
\hline & \multicolumn{2}{|c|}{$(n=3,239)$} & \multicolumn{2}{|c|}{$(n=2,125)$} & \multicolumn{2}{|c|}{$(n=5,364)$} \\
\hline & Median & $(\mathrm{IQR})$ & Median & $(\mathrm{QQR})$ & Median & $(\mathrm{QQR})$ \\
\hline $\mathrm{CO}_{2} \mathrm{e}(\mathrm{kg} / \mathrm{d})$ & 4.4 & 2.0 & 5.3 & 2.3 & 4.7 & 2.2 \\
\hline Age (years) & 32 & 14 & 34 & 12 & 32 & 12 \\
\hline $\mathrm{BMI}\left(\mathrm{kg} / \mathrm{m}^{2}\right)$ & 22.9 & 4.2 & 24.8 & 4.1 & 23.7 & 4.5 \\
\hline Servings of beef/day ${ }^{a}$ & 0.3 & 0.3 & 0.5 & 0.3 & 0.3 & 0.3 \\
\hline Servings of meat/day ${ }^{b}$ & 0.9 & 0.5 & 1.0 & 0.5 & 1.0 & 0.6 \\
\hline Servings of dairy products/day ${ }^{c}$ & 1.1 & 1.2 & 1.2 & 1.5 & 1.1 & 1.4 \\
\hline \multirow[t]{2}{*}{ Servings of dairy products and dishes/day ${ }^{d}$} & 1.2 & 1.2 & 1.3 & 1.5 & 1.2 & 1.4 \\
\hline & $\mathrm{N}$ & $\%^{\mathrm{e}}$ & $\mathrm{n}$ & $\%^{\mathrm{e}}$ & $n$ & $\%^{e}$ \\
\hline \multicolumn{7}{|l|}{ Education (years) ${ }^{\mathrm{e}}$} \\
\hline$<9$ & 44 & 1.4 & 39 & 1.9 & 83 & 1.6 \\
\hline $9-12$ & 757 & 23.5 & 614 & 29.2 & 1,371 & 25.8 \\
\hline$>12$ & 2,134 & 66.3 & 1,286 & 61.2 & 3,420 & 64.3 \\
\hline Other & 283 & 8.8 & 162 & 7.7 & 445 & 8.4 \\
\hline Tobacco users $^{f}$ & 422 & 13.2 & 455 & 21.8 & 877 & 16.6 \\
\hline Supplement use $\mathrm{e}^{\mathrm{g}}$ & 757 & 23.5 & 463 & 21.9 & 1,220 & $22, .9$ \\
\hline
\end{tabular}

Beef, hamburgers and ground meat dishes

${ }^{b}$ Beef, hamburgers, ground meat dishes, pork, bacon, lamb, game, offal, chicken

'Milk, yoghurt, hot cocoa, cheese (hard and soft), ice cream

${ }^{\mathrm{d}}$ Milk, yoghurt, hot cocoa, cheese (hard and soft), ice cream, pancake, pizza

epercentages are averaged why their sum may exceed or not reach $100 \%$

${ }^{f}$ Current smoking and/or snuff use

${ }^{g}$ Users of multivitamin and mineral supplement

multivitamin and/or mineral supplements. The consumption of beef (including ground meat and hamburgers) was 0.3 servings per day for women and 0.5 for men which correspond to 2.1 and 3.5 servings per week, respectively, whereas the consumption of all types of meat was 0.9 and 1.0 per day or 6.3 and 7 servings per week for women and men, respectively. Additional data on nutrient intake is shown in Additional file 1: Table S1.

The distribution of crude daily $\mathrm{CO}_{2} \mathrm{e}$ by age and gender is shown in Fig. 1. The median $\mathrm{CO}_{2} \mathrm{e}$ was lower in women than in men, and increased with age for both women and men. The lower $\mathrm{CO}_{2} \mathrm{e}$ in women compared to men is an effect of lower general intake of energy in women as well as gender differences in what type of food they eat (i.e. higher meat intake in men). Therefore, to take into account differences in energy intake, we present the median and interquartile range (IQR) of absolute nutrient intake according to quartiles of energy adjusted $\mathrm{CO}_{2} \mathrm{e}$ in Table 3 . The intake of nutrients mainly coming from plant-based foods, such as $\beta$-carotene, carbohydrates, polyunsaturated fat, and fiber, were higher in the group with the lowest $\mathrm{CO}_{2} \mathrm{e}$ compared to the group with highest $\mathrm{CO}_{2} \mathrm{e}$, except for the intake of monounsaturated fat, vitamin $\mathrm{C}$ and folate that was higher in the highest $\mathrm{CO}_{2} \mathrm{e}$ group. Nutrients serving as markers for intake of meat and dairy, such as vitamin $B_{12}$, zinc, vitamin $\mathrm{D}$, retinol equivalents, calcium, fat, saturated total fat, and protein, were generally higher in the highest $\mathrm{CO}_{2} \mathrm{e}$ group, compared to the lowest $\mathrm{CO}_{2} \mathrm{e}$ group, whereas there were only small differences regarding the iron intake between $\mathrm{CO}_{2}$ e groups. The overall result did not change when $\mathrm{CO}_{2} \mathrm{e}$ was divided into three groups, i.e. tertiles as well as five groups i.e. quintiles, see Additional file 2: Table S2 and Additional file 3: Table S3.

Figure 2 show the percentage of energy coming from fat, protein, carbohydrates, saturated fat, monounsaturated fat, and polyunsaturated fat, respectively, by quartiles of increasing levels of diet-related $\mathrm{CO}_{2}$ e. Overall, there were small differences between quartiles of $\mathrm{CO}_{2} \mathrm{e}$ and the energy percent for the different macronutrients were in line with recommended intake according to NNR described in Table 1, except for saturated fat which was higher than recommended for all $\mathrm{CO}_{2}$ e groups.

Figure 3 shows the nutrient density (nutrient/MJ) by quartiles of increasing levels of diet-related $\mathrm{CO}_{2} \mathrm{e}$. Hundred percent corresponds to goals for menu planning according to the NNR. Again, there were small differences for vitamins, minerals and fiber between quartiles of $\mathrm{CO}_{2} \mathrm{e}$, except for vitamin $\mathrm{B}_{12}$, where all groups substantially exceeded the recommended intake of $B_{12}$. In contrast, none of the groups reached the recommended intake of folate and vitamin $\mathrm{D}$. 


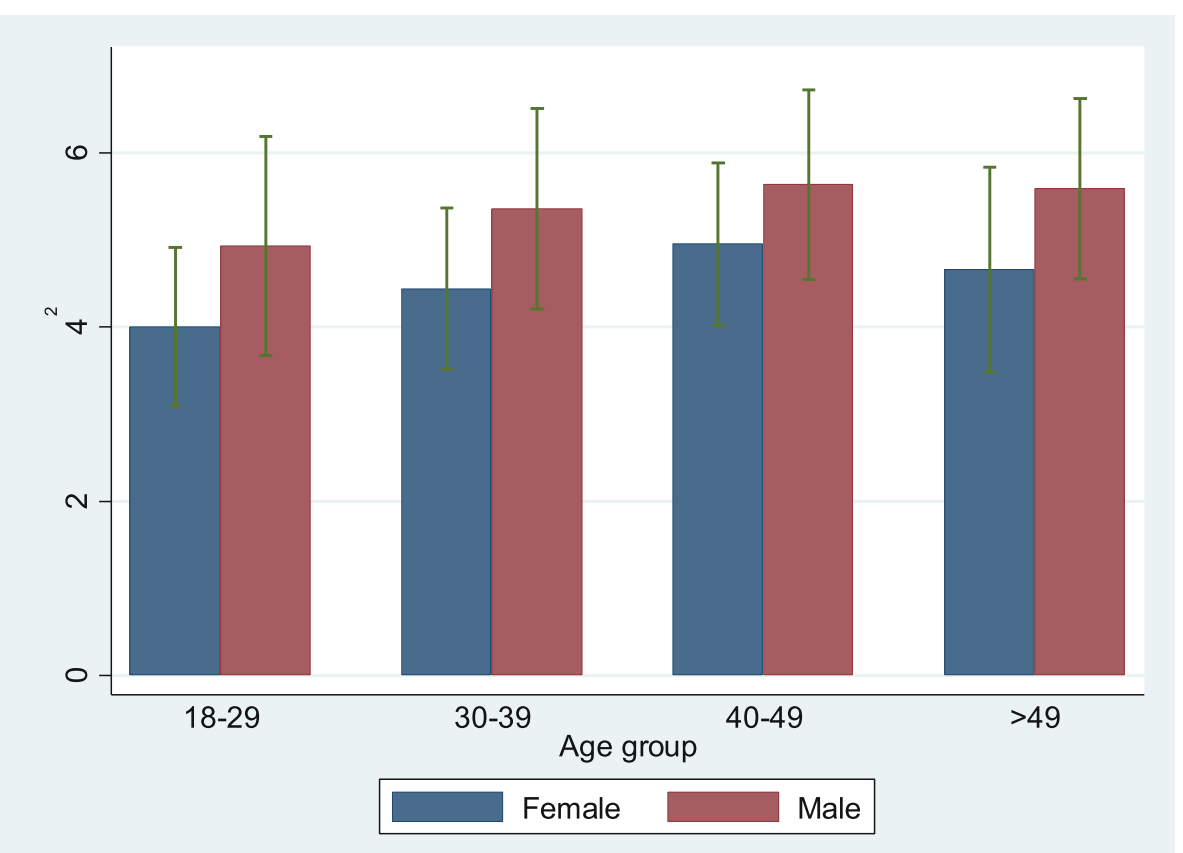

Fig. 1 Diet-related greenhouse gas emissions by age and gender in the LifeGene study, 2009-10, Sweden ( $n=5,364)$. The distribution of crude median and IQR of daily diet-related greenhouse gas emissions expressed as $\mathrm{kg} \mathrm{CO}_{2} \mathrm{e}$ by age and gender

Table 3 Median nutrient intake according to daily diet-related greenhouse gas emissions in the LifeGene study, 2009-10, Sweden

\begin{tabular}{|c|c|c|c|c|c|}
\hline \multirow{3}{*}{ Nutrients } & \multicolumn{5}{|l|}{$\mathrm{kg} \mathrm{CO} 2 \mathrm{e} / \mathrm{d}$} \\
\hline & $0.2-<4.1$ & $4.1-<4.8$ & $4.8-<5.7$ & $5.7-10.9$ & $P$-value \\
\hline & Median (IQR) & Median (IQR) & Median (IQR) & Median (IQR) & \\
\hline Energy $(\mathrm{kJ} / \mathrm{d})$ & $8432(4064)$ & 7396 (2995) & $8086(3081)$ & $8700(3413)$ & $<0.00$ \\
\hline Protein (g/d) & $71.1(35.8)$ & $72.3(28.2)$ & 76.8 (30.6) & $87.6(34.9)$ & $<0.00$ \\
\hline Carbohydrates $(\mathrm{g} / \mathrm{d})$ & $243.1(125.2)$ & $215.0(95.6)$ & $215.9(97.6)$ & $219.1(102.2)$ & $<0.00$ \\
\hline Fat $(g / d)$ & $64.8(37.3)$ & $62.6(27.9)$ & $65.1(28.8)$ & $70.5(32.5)$ & $<0.00$ \\
\hline Saturated fat (g/d) & $24.0(14.9)$ & $23.5(11.6)$ & $24.7(12.6)$ & $27.2(13.1)$ & $<0.00$ \\
\hline Monounsaturated fat (g/d) & $23.9(13.4)$ & $23.1(10.5)$ & $24.1(11.2)$ & $26.1(12.1)$ & $<0.00$ \\
\hline Polyunsaturated fat $(\mathrm{g} / \mathrm{d})$ & $11.3(7.3)$ & $10.4(5.6)$ & $10.6(5.7)$ & $10.7(5.6)$ & $<0.00$ \\
\hline$\beta$-carotene $(\mu \mathrm{g} / \mathrm{d})$ & $2,514(2,766)$ & $2,317(2,350)$ & $2,445(2,440)$ & $2,481(2,326)$ & 0.07 \\
\hline Vitamin C (mg/d) & $92.0(71.2)$ & $95.5(66.9)$ & $99.3(71.3)$ & $103.9(75.6)$ & $<0.00$ \\
\hline Folate $(\mu \mathrm{g} / \mathrm{d})^{2}$ & $296.4(192.2)$ & $287.5(143.5)$ & $291.3(140.1)$ & 302. $3(146.8)$ & $<0.00$ \\
\hline Fiber $(\mathrm{g} / \mathrm{d})$ & $24.8(18.0)$ & $22.2(13.2)$ & $21.7(11.6)$ & $21.1(11.5)$ & $<0.00$ \\
\hline Vitamin B12 ( $\mu \mathrm{g} / \mathrm{d})$ & $3.7(2.6)$ & $4.3(2.2)$ & $4.8(2.3)$ & $5.8(2.9)$ & $<0.00$ \\
\hline $\operatorname{Iron}(\mathrm{mg} / \mathrm{d})^{3}$ & $13.4(8.3)$ & $12.5(6.4)$ & $12.9(6.1)$ & $13.6(6.2)$ & $<0.00$ \\
\hline Zinc $(\mathrm{mg} / \mathrm{d})$ & $9.7(5.2)$ & $9.7(4.0)$ & $10.3(4.2)$ & $11.7(4.6)$ & $<0.00$ \\
\hline Vitamin $D(\mu \mathrm{g} / \mathrm{d})$ & $4.8(3.7)$ & $5.4(3.2)$ & $5.9(3.1)$ & $7.0(3.8)$ & $<0.00$ \\
\hline Retinol $(\mu \mathrm{g} / \mathrm{d})$ & $364.8(310.3)$ & $388.2(270.9)$ & $423.8(254.6)$ & $464.7(303.2)$ & $<0.00$ \\
\hline Retinol equivalents (RE/d) & $674.4(450.1)$ & $652.5(392.5)$ & $685.2(386.8)$ & $724.3(426.5)$ & $<0.00$ \\
\hline Calcium (mg/d) & $816.4(511.3)$ & $849.6(443.4)$ & $947.4(457.9)$ & $1,055.5(574.0)$ & $<0.00$ \\
\hline
\end{tabular}

Median and interquartile range (IQR) of nutrient intake according daily diet-related greenhouse gas emissions $\left(\mathrm{CO}_{2} \mathrm{e}\right)$ adjusted for total energy intake among 5,364 men and women in the LifeGene study

${ }^{1}$ Kruskal-Wallis p-values

${ }^{2}$ For women only: the intake of folate was $301.7,295.4,297.4,310.8 \mu \mathrm{g} / \mathrm{d}$ for varying levels of $\mathrm{kg} \mathrm{CO}_{2} \mathrm{e} / \mathrm{d}$

${ }^{3}$ For women only: the intake of iron was $13.1,12.5,12.5,13.2 \mathrm{mg} / \mathrm{d}$ for varying levels of $\mathrm{kg} \mathrm{CO}_{2} \mathrm{e} / \mathrm{d}$ 


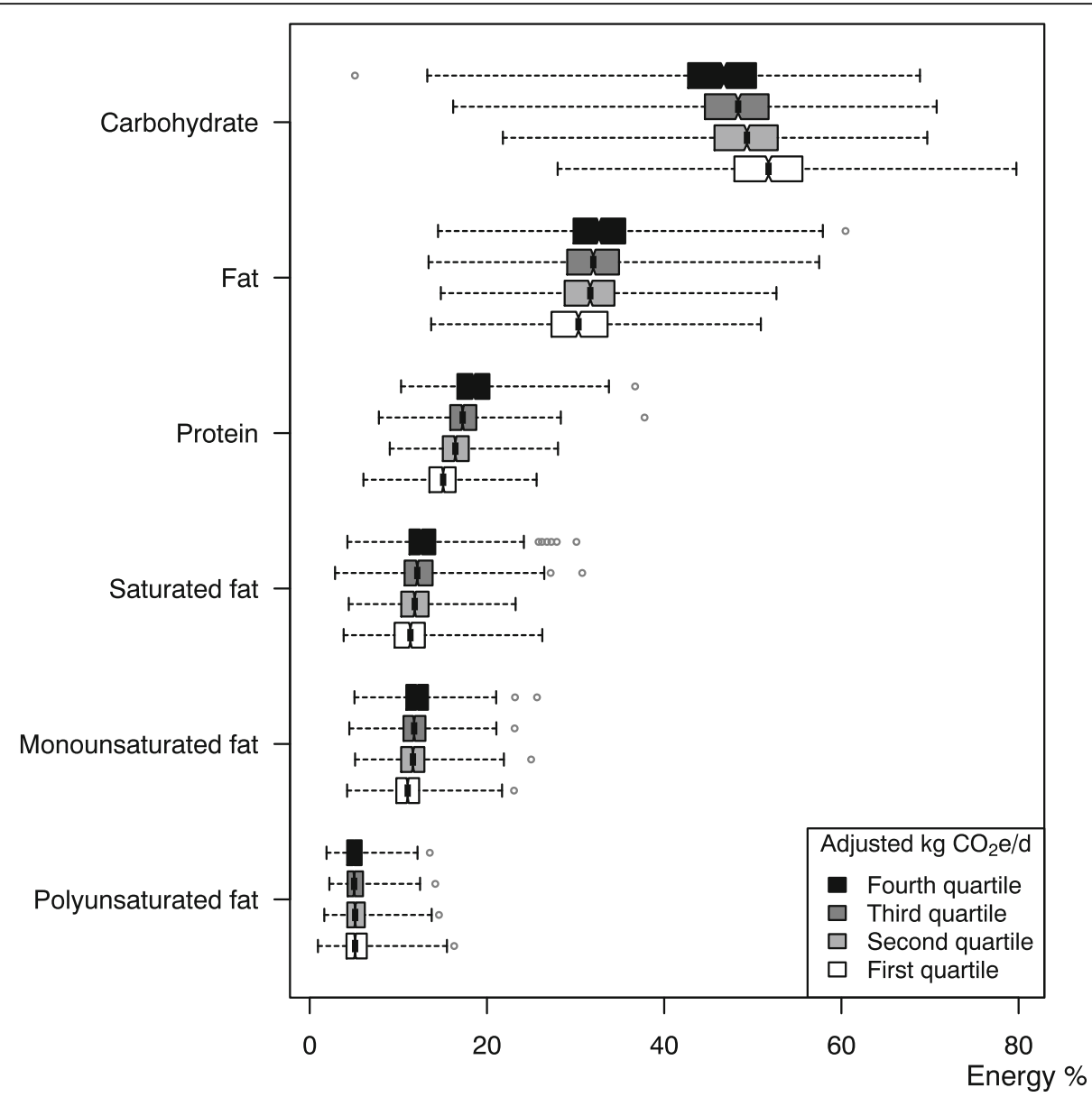

Fig. 2 Percentage of energy coming from macronutrients by quartiles of increasing levels of greenhouse gas emissions in the LifeGene study, 2009-10, Sweden $(n=5,364)$. The percentage of energy coming from fat, protein, carbohydrates, saturated fat, monounsaturated fat, and polyunsaturated fat, respectively, by quartiles of increasing levels of energy adjusted diet-related greenhouse gas emissions

Moreover, for fiber, only the group with the lowest $\mathrm{CO}_{2} \mathrm{e}$ reached recommended intake.

\section{Discussion}

The group with the lowest $\mathrm{CO}_{2}$ e emissions had adequate intake of most nutrients, and the intake was comparable with the nutrient intake among people in the highest $\mathrm{CO}_{2} \mathrm{e}$ emissions, suggesting that a diet low in GHGE can be nutritious at the same time. Although the intake of some important nutrients increased with increasing emissions in our study, there were only small differences between groups with varying $\mathrm{CO}_{2} \mathrm{e}$ levels and the effect was less pronounced compared to a study by Vieux et al 2013 where an indicator of good nutritional quality dietary was significantly higher for a diet high in GHGE compared to a diet low in GHGE [9].

Compared to the NNR [15], the median intake of micronutrients was generally near or above the recommended intakes when analyzed as nutrient density in all $\mathrm{CO}_{2} \mathrm{e}$ groups in the present study. The trend was similar for energy percent of macronutrients, where the intake was within recommended levels, except for saturated fat which was higher than recommended. In general, all $\mathrm{CO} 2 \mathrm{e}$ groups fulfilled the recommended intake of iron, B12, zinc, retinol equivalents, nutrients mainly found in animal products. Highest intake of $\mathrm{B} 12$ and zinc were found in the group with the highest $\mathrm{CO}_{2} \mathrm{e}$, whereas there were no differences for iron and retinol equivalents. However, the intake of folate did not reach the recommended level for women in reproductive age, which is a majority of the females in this study. Nor did any of the groups have enough intake of vitamin $\mathrm{D}$, a common problem in the general population in Sweden.

This study has several strengths and limitations that should be considered. A main strength is the use of individually assessed dietary information from a large population-based study, which allows for analyses of individual variability in $\mathrm{CO}_{2} \mathrm{e}$, whereas many studies in this area rely on simulated dietary scenarios, such as comparisons between meals, dietary patterns or 


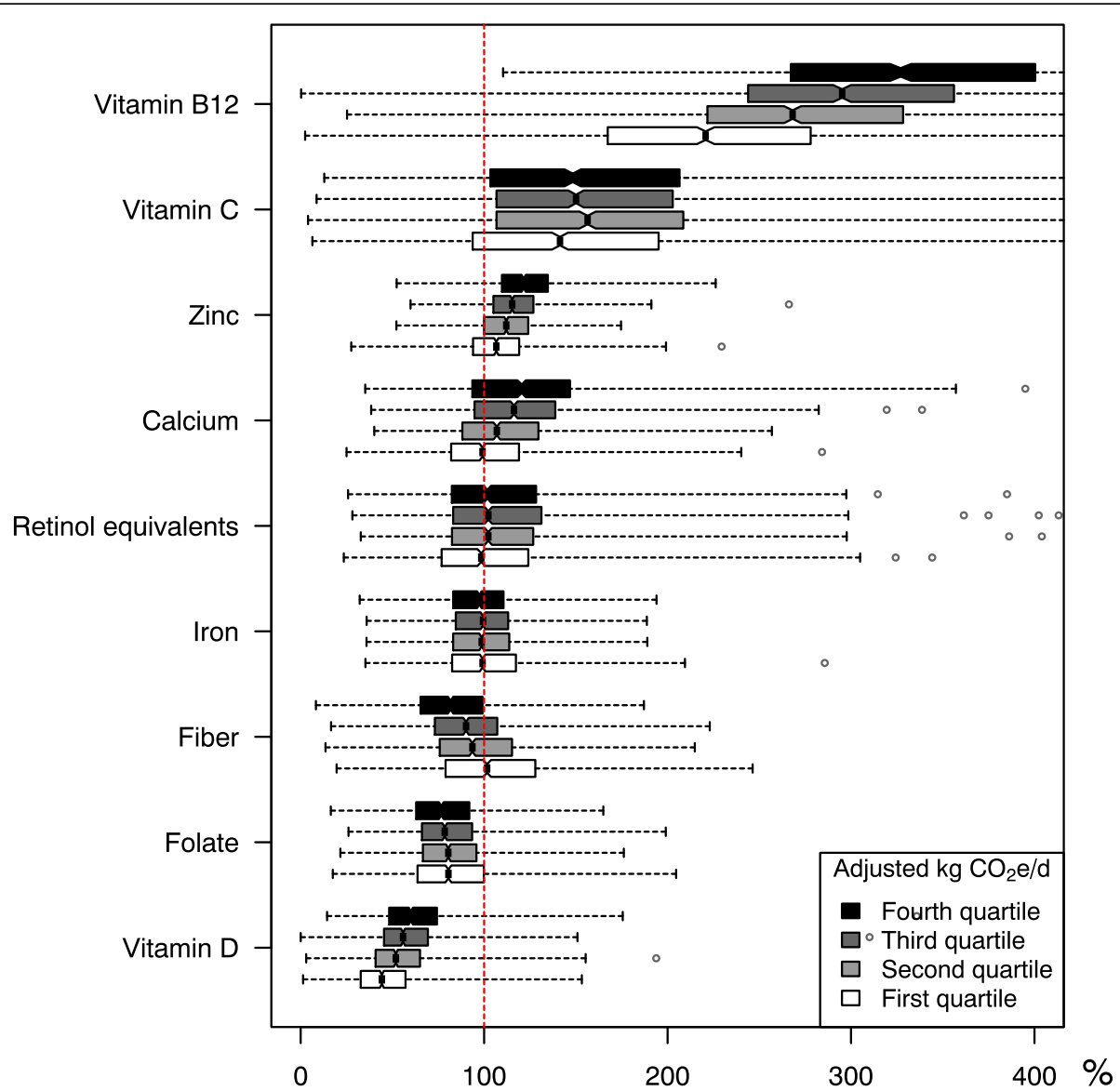

Fig. 3 The nutrient density (nutrient/MJ) by quartiles of increasing levels of greenhouse gas emissions in the LifeGene study, 2009-10, Sweden $(n=5,364)$. The nutrient density (nutrient/MJ) by quartiles of increasing levels of energy adjusted diet-related greenhouse gas emissions. Hundred percent corresponds to nutrient density goals for menu planning according to the Nordic Nutrition Recommendation

national consumption statistics [4, 26, 27]. Also, the magnitude of the $\mathrm{CO}_{2} \mathrm{e}$ reported in this study is comparable to Bryngelsson et al 2016 [1], where similar LCA data were linked to consumption data based on national statistics from Sweden. Moreover, the daily emissions of $\mathrm{CO}_{2} \mathrm{e}$ was comparable to other studies based on individually assessed dietary intake using FFQ [6-8]. The dietary assessment method that was used, Meal-Q, was developed and validated by us for the LifeGene study $[18,19]$, and showed strong validity and reproducibility [21]. A limited number of studies have analyzed $\mathrm{CO}_{2} \mathrm{e}$ from self-selected diets assessed in surveys or cohort studies [6-9], but to our knowledge, this is the first study based on a Swedish population. Also, this is the first observational study looking at the relation between $\mathrm{CO}_{2} \mathrm{e}$, and adherence to NNR with regards to individual nutrients. This study therefore contributes with substantial new knowledge about a diet low in GHGE based on a self-selected diet.

Differences in assumptions and methodologies between LCA studies, such as allocations and system boundaries, make comparisons between studies complicated. Product specific variations, such as use of fuel for transports, fodder for the animals, electricity mix etc. have impacts on emissions linked to each product. Moreover, the functional unit may differ, for instance, if $\mathrm{CO}_{2} \mathrm{e}$ is expressed for meat with or out without bones. In this study, we have taken several steps to ensure that the LCA data accurately represent food consumption in Sweden. First, the result is based on a large number of LCA studies (65 food groups) that matches the food items in dietary questionnaire [21]. Second, most LCA data used in this study have the same system boundaries and surrounding system. Thirdly, the LCA data were recalculated taking into account weight change during cooking. Finally, we included avoidable and unavoidable waste on a household level using different values for different products [23, 24], for example, the proportion of waste is greater for fresh foods than for staple food. Although, the total estimated emissions per person may be somewhat biased, it allows us to rank individuals and make comparisons between 
groups of people with high and low emissions, respectively [25] and extensive sensitivity analyses show that the results are robust and did not differ when $\mathrm{CO}_{2} \mathrm{e}$ was divided into tertiles, quartiles or quintiles.

The cross-sectional design of the study is a limitation. Also, systematic bias may be introduced when linking data on emissions to dietary information. The FFQ is designed to capture most of the diet and the food items listed in the questionnaire is representative for main stream food habits in the population, i.e. it does not capture the whole diet [18]. Moreover, for mixed dishes, such as lasagna, we rely on standard recipes [20] and used weighted LCA data for up to three main food products or groups [21]. Also, underreporting is one of the most challenging problems with all self-reported dietary assessments, and some foods are thought to be underreported to a greater extent than others, as well as vary between groups [25]. Thus, the absolute $\mathrm{CO}_{2} \mathrm{e}$ is therefore underestimated in the present study as compared to if a more extensive dietary method had been used [21].

\section{Conclusions}

In conclusion, the magnitude of the diet-related $\mathrm{CO}_{2} \mathrm{e}$ in the present observational study is in line with result from other studies, both scenarios and self-selected diets. Moreover, it shows that a self-selected diet low in $\mathrm{CO}_{2} \mathrm{e}$ provides comparable intake of nutrients associated with vegetables, fruits, meat and dairy, as a diet high in $\mathrm{CO}_{2} \mathrm{e}$. Also, it shows that a diet low in $\mathrm{CO}_{2} \mathrm{e}$ adhere to dietary guidelines for most nutrients. This opens up for a future win-win situation between a diet low in GHGE and a nutritious diet. Our collective food choices have significant impact on global GHGE and in order to reduce climate impact from food, the consumption of meat, in particular beef, should be reduced and the consumption of plant-based foods, such as whole grains, legumes, vegetables and fruit increase.

\section{Additional files}

Additional file 1: Table S1. Nutrient intake among women and men in the Swedish LifeGene study in 2009-10. (DOCX 14 kb)

Additional file 2: Table S2. Median nutrient intake divided by tertiles of $\mathrm{CO}_{2} \mathrm{e}$ adjusted for total energy intake among 5,364 men and women in the LifeGene study, 2009-10, Sweden. (DOCX $17 \mathrm{~kb}$ )

Additional file 3: Table S3. Median nutrient intake divided by quintiles of $\mathrm{CO}_{2} \mathrm{e}$ adjusted for total energy intake among 5,364 men and women in the LifeGene study, 2009-10, Sweden. (DOCX 18 kb)

\section{Abbreviations}

$\mu \mathrm{g}$ : Microgram; BMI: Body mass index; $\mathrm{CO}_{2} \mathrm{e}$ : Carbon dioxide equivalents; FFQ: Food frequency questionnaire; GHGE: Greenhouse gas emission; GWP: Global warming potential; IQR: Interquartile range; kJ: Kilo joule; LCA: Life cycle assessment; Mg: Milligram; MJ: Mega joule; NNR: Nordic nutrition recommendations

\section{Acknowledgements}

We would like to thank the participants in the LifeGene study as well as Jonas Karlström for invaluable assistance with the calculations of $\mathrm{CO}_{2} \mathrm{e}$ and nutrients.

\section{Funding}

The present work was supported by grants from the Swedish Research Council, The Alpro Foundation and Riksbankens Jubileumsfond, and the data collection of LifeGene was supported by Torsten and Ragnar Söderberg's Foundation, and AFA Insurances.

\section{Availability of data and supporting materials}

The database on $\mathrm{CO}_{2} \mathrm{e}$ used to calculated daily $\mathrm{CO}_{2} \mathrm{e}$ has been published by us and is found in Sjörs et al. Environmental Health (2016).

The dataset, i.e. data based on questionnaires, used for this manuscript is not publically available at this time. However, the LifeGene study is national resource and researchers may apply directly to LifeGene to access the data from the ongoing study.

\section{Authors' contributions}

CS and FH were responsible for collecting LCA data; CS recalculated LCA data and linked LCA data to food items; KB developed and validated of the calculation program NutriCalc; AT, AS, and KB was responsible for statistical analyses and interpretation of results; $\mathrm{KB}$ drafted the manuscript; $\mathrm{KB}, \mathrm{CS}$, $\mathrm{FH}$, CG, AT and AS contributed substantially to the revision of the manuscript and all authors read and approved the final manuscript.

\section{Competing interests}

The authors declare that they have no competing interests.

\section{Consent for publication}

The manuscript does not contains any individual person's data in any form (including individual details, images or videos), and therefore, we have not requested consent to publish from any person.

\section{Ethics approval and consent to participate}

The Research Ethics Review Board at Karolinska Institutet approved the present study and each participant signed a consent forms.

\section{Author details}

'Department of Medical Epidemiology and Biostatistics, Karolinska Institutet, Nobels väg 12a, 17177 Stockholm, Sweden. ${ }^{2}$ Stanford Prevention Research Center, Stanford School of Medicine, Stanford, USA. ${ }^{3}$ Division of Public Health Sciences, School of Health, Care and Social Welfare, Mälardalen University, Västerås, Sweden. ${ }^{4}$ Department of Energy and Environment, Chalmers University of Technology, Gothenburg, Sweden.

Received: 1 June 2016 Accepted: 16 February 2017 Published online: 10 April 2017

\section{References}

1. Bryngelsson D, Wirsenius S, Hedenus F, Sonesson U. How can the EU climate targets be met? A combined analysis of technological and demandside changes in food and agriculture. Food Policy. 2016;59:152-64.

2. Carlsson-Kanyama A, Gonzalez AD. Potential contributions of food consumption patterns to climate change. Am J Clin Nutr. 2009;89(5):S1704-9.

3. Hedenus F, Wirsenius S, Johansson DJA. The importance of reduced meat and dairy consumption for meeting stringent climate change targets. Clim Chang. 2014;124(1-2):79-91.

4. Saxe H, Larsen TM, Mogensen L. The global warming potential of two healthy Nordic diets compared with the average Danish diet. Clim Chang. 2013;116(2):249-62.

5. Davis J, Sonesson U, Baumgartner DU, Nemecek T. Environmental impact of four meals with different protein sources: Case studies in Spain and Sweden. Food Res Int. 2010:43(7):1874-84.

6. Biesbroek S, Bueno-de-Mesquita HB, Peeters PH, Verschuren WM, van der Schouw YT, Kramer GF, et al. Reducing our environmental footprint and improving our health: greenhouse gas emission and land use of usual diet and mortality in EPIC-NL: a prospective cohort study. Environ Health. 2014; 13(1):27. 
7. Scarborough P, Appleby PN, Mizdrak A, Briggs AD, Travis RC, Bradbury KE, Key TJ. Dietary greenhouse gas emissions of meat-eaters, fish-eaters, vegetarians and vegans in the UK. Clim Change. 2014;125(2):179-92.

8. Soret S, Mejia A, Batech M, Jaceldo-Siegl K, Harwatt H, Sabate J. Climate change mitigation and health effects of varied dietary patterns in real-life settings throughout North America. Am J Clin Nutr. 2014;100 Suppl 1:490S-5S.

9. Vieux F, Soler L-G, Touazi D, Darmon N. High nutritional quality is not associated with low greenhouse gas emissions in self-selected diets of French adults. Am J Clin Nutr. 2013;97(3):569-83.

10. Temme EH, Toxopeus IB, Kramer GF, Brosens MC, Drijvers JM, Tyszler M, et al. Greenhouse gas emission of diets in the Netherlands and associations with food, energy and macronutrient intakes. Public Health Nutr. 2015; 18(13):2433-45.

11. Temme EH, van der Voet H, Thissen JT, Verkaik-Kloosterman J, Van Donkersgoed G, Nonhebel S. Replacement of meat and dairy by plantderived foods: estimated effects on land use, iron and SFA intakes in young Dutch adult females. Public Health Nutr. 2013;16(10):1900-7.

12. Edenhofer O, Pichs-Madruga R, Sokona Y, Kadner S, Minx JC, Brunner S, Agrawala G. S, et al. Technical Summary. In: Edenhofer O, Pichs-Madruga R, Sokona Y, Farahani E, Kadner S, Seyboth A. K, et al., editors. Climate Change 2014: Mitigation of Climate Change. Cambridge: Contribution of Working Group III to the Fifth Assessment Report of the Intergovernmental Panel on Climate Change; 2014

13. Intergovernmental panel on climate change. [http://www.ipcc.ch/]

14. Commission E: Environmental Impact of Products (EIPRO). Analysis of the Life Cycle Environmental Impacts Related to the Final Consumption of the EU 25 2006. In: Contract No: European Commission Technical Report EUR 22284 EN. 2006.

15. Nordic Council of Minister. Nordic Nutrition Recommendations: integrating nutrition and physical activity. 5th ed. Copenhagen: Nordic Council of Minister; 2012.

16. LifeGene [www.lifegene.se]

17. Almqvist C, Adami HO, Franks PW, Groop L, Ingelsson E, Kere J, et al. LifeGene-a large prospective population-based study of global relevance. Eur J Epidemiol. 2011;26(1):67-77.

18. Christensen SE, Moller E, Bonn SE, Ploner A, Wright A, Sjolander A, et al. Two new meal- and web-based interactive food frequency questionnaires: validation of energy and macronutrient intake. J Med Internet Res. 2013; 15(6), e109.

19. Christensen SE, Moller E, Bonn SE, Ploner A, Balter O, Lissner L, et al. Relative validity of micronutrient and fiber intake assessed with two new interactive meal- and Web-based food frequency questionnaires. J Med Internet Res. 2014;16(2), e59.

20. Food composition table [https://www.livsmedelsverket.se/en/]

21. Sjors C, Raposo SE, Sjolander A, Balter O, Hedenus F, Balter K. Diet-related greenhouse gas emissions assessed by a food frequency questionnaire and validated using 7-day weighed food records. Environ Health. 2016;15(1):15.

22. Myhre GD, Shindell FM, Bréon W, Collins J, Fuglestvedt J, Huang D, et al. Anthropogenic and Natural Radiative Forcing. In: Stocker TFD, Qin G-K, Plattner M, Tignor SK, Allen J, Boschung A, et al., editors. Climate Change 2013: The Physical Science Basis Contribution of Working Group I to the Fifth Assessment Report of the Intergovernmental Panel on Climate Change. Cambridge: Cambridge University Press; 2013.

23. Quested TJH. Household Food and Drink Waste in the UK. In: Report prepared by Waste and Resources Action Programme (WRAP) ISBN: 184405-430-6. Banbury. 2009.

24. Gustavsson JCC, Sonesson U, Emanuelsson A. The methodology of the FAO study. Göteborg: Global Food Losses and Food Waste - extent, causes and prevention; 2013.

25. Willett W. Nutritional Epidemiology. 3rd ed. Oxford: Monographs in Epidemiology and Biostatistics; 2013.

26. Wallen A, Brandt N, Wennersten R. Does the Swedish consumer's choice of food influence greenhouse gas emissions? Environ Sci Pol. 2004;7(6):525-35.

27. Risku-Norja HKS, Helenius J. Impact of consumers' diet choices on greenhouse gas emissions. In: Future of the Consumer Society 2009. Tampere: Finland Futures research Center; 2009. p. 159-70.

\section{Submit your next manuscript to BioMed Central and we will help you at every step:}

- We accept pre-submission inquiries

- Our selector tool helps you to find the most relevant journal

- We provide round the clock customer support

- Convenient online submission

- Thorough peer review

- Inclusion in PubMed and all major indexing services

- Maximum visibility for your research

Submit your manuscript at www.biomedcentral.com/submit
) Biomed Central 